\title{
Applications of internet of things for monitoring drivers- a comprehensive study
}

\author{
Sumendra Yogarayan', Siti Fatimah Abdul Razak', Afizan Azman², Mohd. Fikri Azli Abdullah ${ }^{1}$ \\ ${ }^{1}$ Faculty of Information Science and Technology (FIST), Multimedia University (MMU), Melaka, Malaysia \\ ${ }^{2}$ Research and Innovation (R\&I), Kolej Universiti Islam Melaka (KUIM), Melaka, Malaysia
}

\begin{tabular}{l} 
Article Info \\
\hline Article history: \\
Received May 29, 202 \\
Revised Nov 17, 2021 \\
Accepted Dec 28, 202 \\
\hline Keywords: \\
Alcohol concentration \\
Driving \\
Health abnormalities \\
Internet of things \\
Tool
\end{tabular}

\begin{abstract}
Driving is a complex task that involves interacting adequately with the vehicle and the environmental changes simultaneously. Drivers' health is an essential factor in determining performance outcomes and enhancing road safety. It is a known reality that drivers with sudden health complications are most likely to be involved in road accidents and suffer several injuries. Besides that, drunk driving is another aspect of a significant public health issue, where drivers under the influence of alcohol show a clear vision loss and vehicle control. The internet of things (IoT) is a trendsetting advancement in which all sensor data can be collected in the cloud. In this paper, an active monitoring tool is developed to record the driver's heart rate if these readings reach vital values while on the move. Additionally, the tool monitors the driver's alcohol concentration, and if it rises beyond a certain threshold, an alarm is sent to the designated emergency contact. The tool has been tested and has been found to work satisfactorily.
\end{abstract}

This is an open access article under the CC BY-SA license.

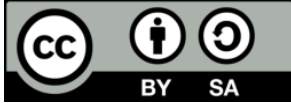

\section{Corresponding Author:}

Afizan Azman

Research and Innovation (R\&I), Kolej Universiti Islam Melaka (KUIM)

Batu 28, Kuala Sungai Baru, 78200 Melaka, Malaysia

Email: afizan@kuim.edu.my

\section{INTRODUCTION}

The internet of things (IoT) directly links thousands of cutting-edge technologies such as sensors, processors, nodes, switches, and networks. These physical devices communicate and interact wirelessly. Interconnected devices exchange information and data without user interaction [1], [2]. The widespread rollout of IoT in manufacturing industries was first observed to incorporate flexibility and reduced production costs. Ultimately, its applicability has evolved into more commercial and general use [3]-[4]. Nevertheless, the possibilities that IoT brings to the automotive industry are truly enormous. There are different kinds of use cases IoT has advanced for the way people relate with their vehicles. These are summarised in Figure 1 [5].

The fundamental notion of the IoT can significantly improve the standard of living and safety of drivers on the road. According to recent research published by the World Health Organization (WHO), a percentage of road accidents are caused by sudden health abnormalities that develop while driving under certain circumstances [6]. Additionally, there has been an increase in drunk driving, resulting in numerous deaths and damage to many on-side properties [7]. According to the ministry of transport, while road safety statistics have improved over the past two years, there are even more opportunities to reduce fatalities and severe injuries on the roads [8], [9]. On another note, the authorities also warned that technology is only the start, as it is necessary to cultivate the right mentality to act on the collected data [10].

IoT is a combination of the two terms that are Internet and things. The first term is the internet; the internet is defined as a network that offers a wide range of information and connectivity connecting thousands 
of users to specific typical internet protocols [11]. Various sectors and departments are connected via the Internet through multiple technologies to maintain communication and transfer relevant information. Several technologies such as computers, mobile phones, and business organisations connect to the internet [12]. The second term is things; things are those objects that become intelligent by putting in a technological device [13]. Thus, integrating IoT and vehicles can provide an assistance system that can monitor driver health abnormalities or alcohol levels to prevent crashes while driving on the road [14]-[16]. The following section will address health abnormalities and alcohol in greater detail.

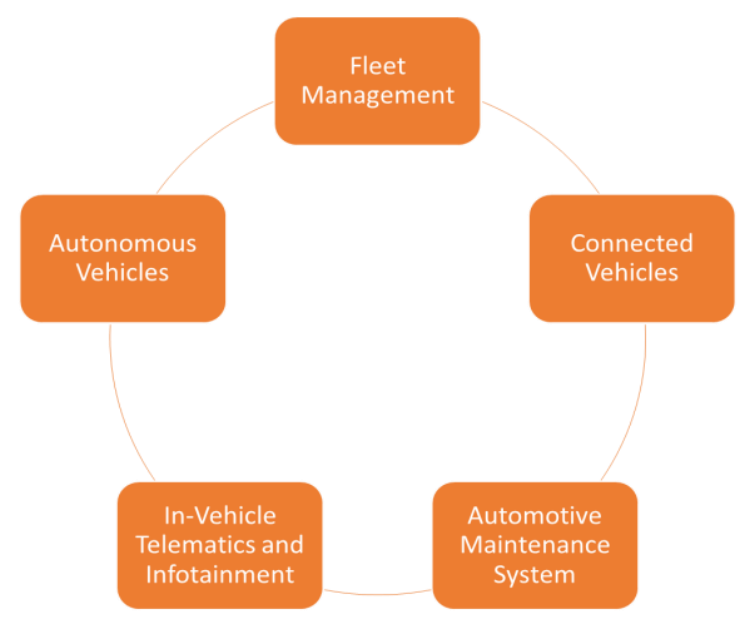

Figure 1. Different IoT use case for vehicles [5]

Health abnormalities are described as a condition or behaviour that is not usual or different from what is considered normal [17]. An example of health abnormalities is heart episodes. Heart episodes can take place at any time, including while driving on the road [18]-[20]. One in four deaths is related to heart disease, making it a fraction of the cause of death [21]. Common heart diseases include coronary heart disease (CAD), which can weaken the heart and cause heart failure [18]. Furthermore, an irregular heartbeat, also known as arrhythmia, with atrial fibrillation (AFib) is another frequent cause of heart failure [22]. For instance, some cases related to sudden heart failure or seizures while driving has resulted in severe injuries to road users in Malaysia. Figure 2 briefly shows the chronology of specific use cases. Several research studies have also uncovered a framework that monitors heart rate, as shown in Table 1.

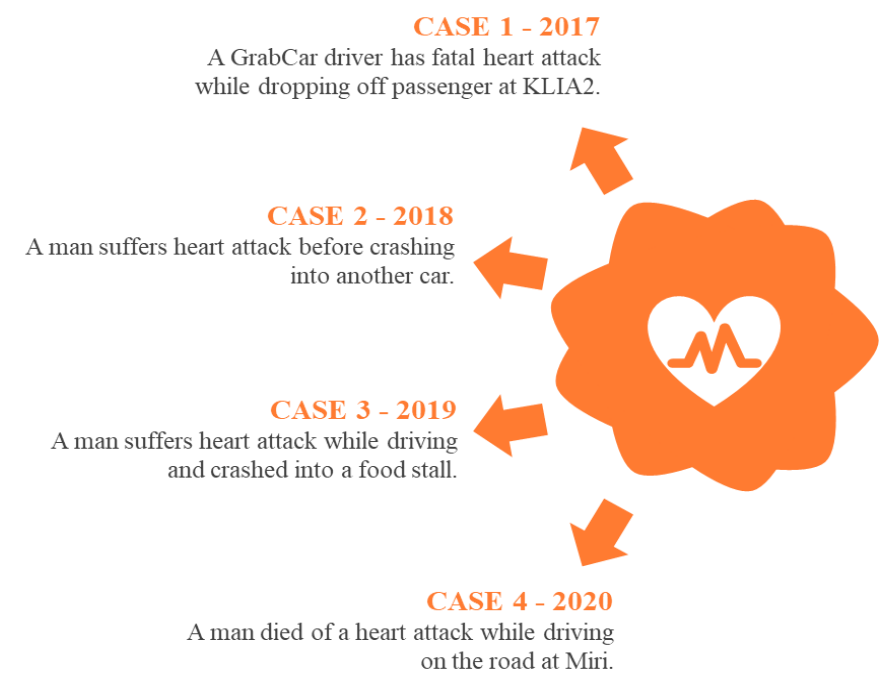

Figure 2. Use cases of heart attack while driving in Malaysia [23]-[26] 
Table 1. Previous studies on health state monitoring

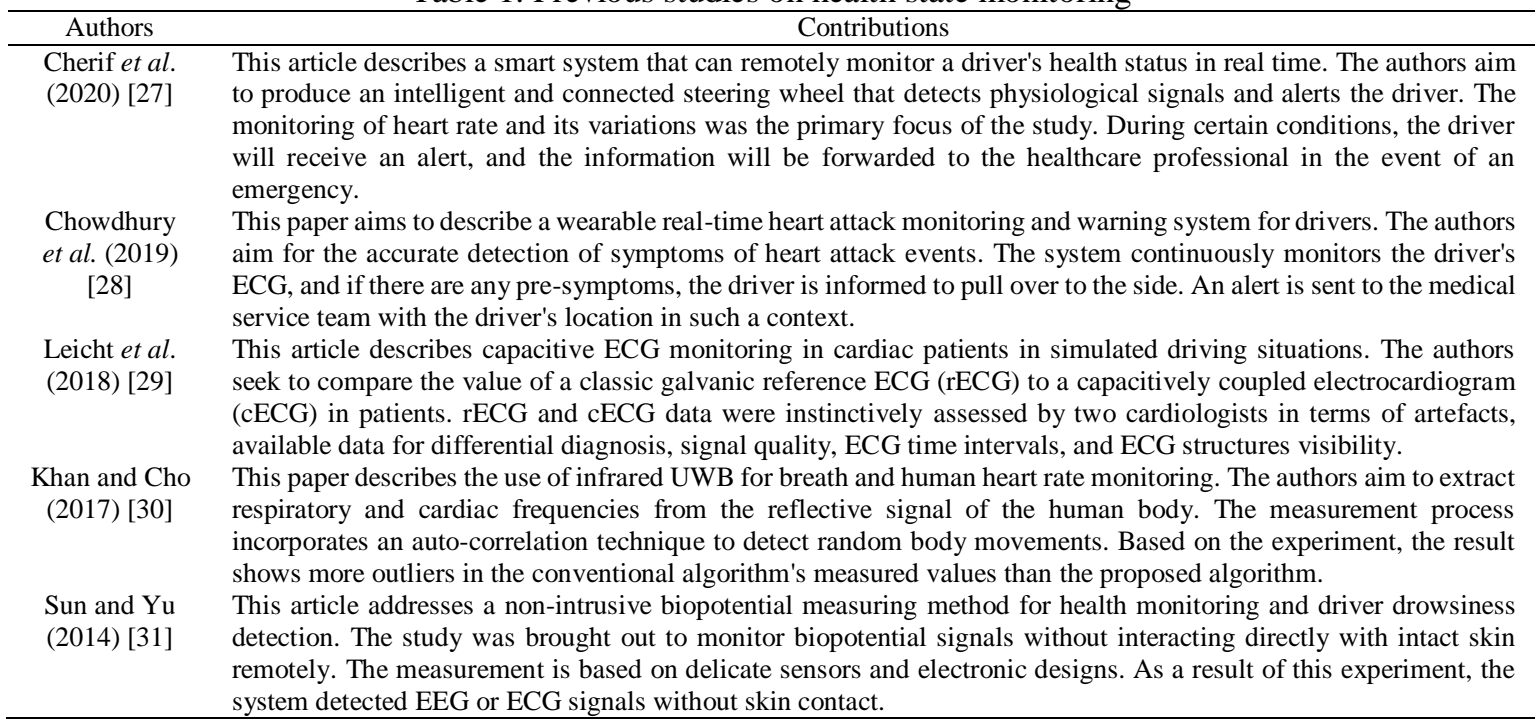

Driving with blood alcohol content (BAC) is sometimes referred to as driving under the influence of alcohol (DUI) or impaired driving (ID) [32], [33]. Any amount of alcohol in an individual's bloodstream can affect their ability to drive. The effects of alcohol consumption vary greatly, which means that a person is at risk of causing an accident or injury on the road [34], [35]. On average, alcohol-related accidents are the highest in the majority of Asian countries [36]. For example, a few cases are associated with the risk of alcohol accidents in Malaysia, including the person causing severe injury and even death to other road users. Figure 3 briefly shows the sequence of events of specific use cases. Several research projects have also identified a framework for monitoring alcohol levels in drivers, as shown in Table 2.

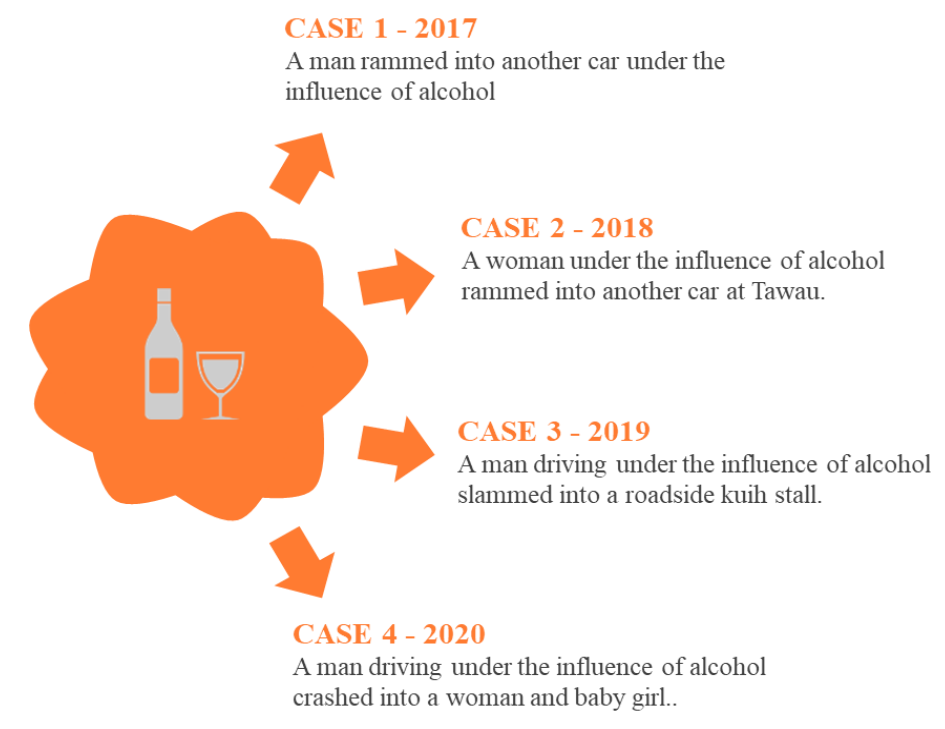

Figure 3. Use cases of alcohol consumption while driving in Malaysia [37]-[40]

Thus, this paper presents a tool that monitors the heart rate and detects the alcohol concentration of drivers while on the move. If the readings reach a vital level in the state, the emergency contact will be notified, and the readings will also be sent to the cloud for further analysis. This paper is organised as follows; Section 2 elaborates on its importance for monitoring drivers specifically in terms of health abnormalities and alcohol. The framework of the proposed work is shown in section 3. In section 4, the testing outcomes are presented. In the last section, the conclusion and future direction are highlighted. 
Table 2. Previous studies on alcohol level detection

\begin{tabular}{|c|c|}
\hline Authors & Contributions \\
\hline $\begin{array}{l}\text { Shukla et al. } \\
(2020)[41]\end{array}$ & $\begin{array}{l}\text { This paper describes an automatic engine locking system due to alcohol detection. The authors aim to design a } \\
\text { continuous monitoring tool of alcohol concentration. The prototype includes several sensors and hardware modules } \\
\text { that monitor constantly. If the attention is above the threshold value, a message is sent to the smartphone of the current } \\
\text { vehicle location. }\end{array}$ \\
\hline $\begin{array}{c}\text { Mandal et al. } \\
(2020)[42]\end{array}$ & $\begin{array}{l}\text { This article describes a system for detecting alcohol and checking the safety belt. The authors seek to develop a } \\
\text { system to ensure that drivers wear seatbelts and are alcohol-free before driving. The development includes } \\
\text { connectivity of the processing unit as well as sensors. This experiment demonstrated that the prototype could } \\
\text { determine the state of the seat belt and the concentration of alcohol. }\end{array}$ \\
\hline $\begin{array}{l}\text { Wakana et al. } \\
\text { (2018) [44] }\end{array}$ & $\begin{array}{l}\text { This article discusses a portable alcohol detection device that is capable of respiratory recognition. The authors choose } \\
\text { to create a portable device that detects alcohol in the breath using a non-contact breath detector. The device comprises } \\
\text { a casing with input for breathing, a USB connection for connecting a smartphone, and a PCB. During the experiment, } \\
\text { the equipment was able to identify saturated water vapour and human breath metabolite. }\end{array}$ \\
\hline
\end{tabular}

\section{METHOD}

The main idea behind this work is to develop a kind of tool to monitor the driver's heart rate and alcohol concentration while on the road. The main component used for the design of this project is arduino UNO, MQ3 sensor, impulse sensor, GSM module, buzzer, and LEDs. The working principle is shown in Figure 4, while the flowchart diagram is shown in Figure 5.

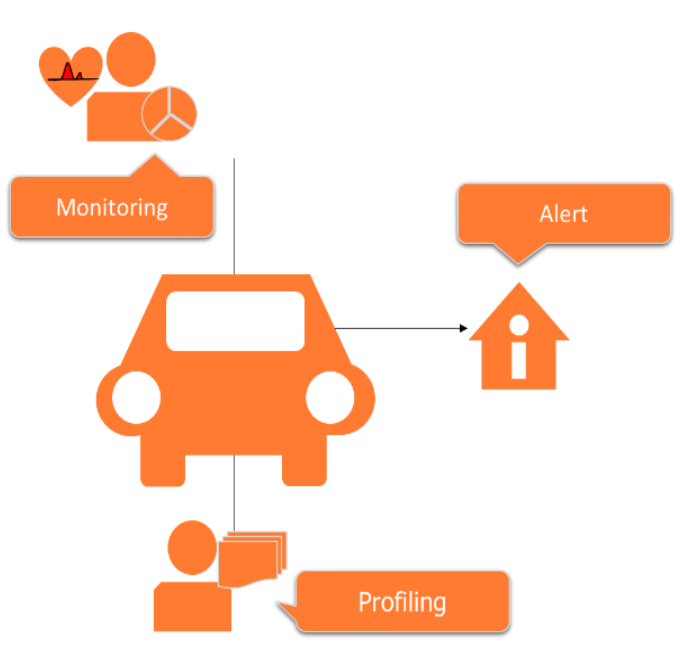

Figure 4. Working principle

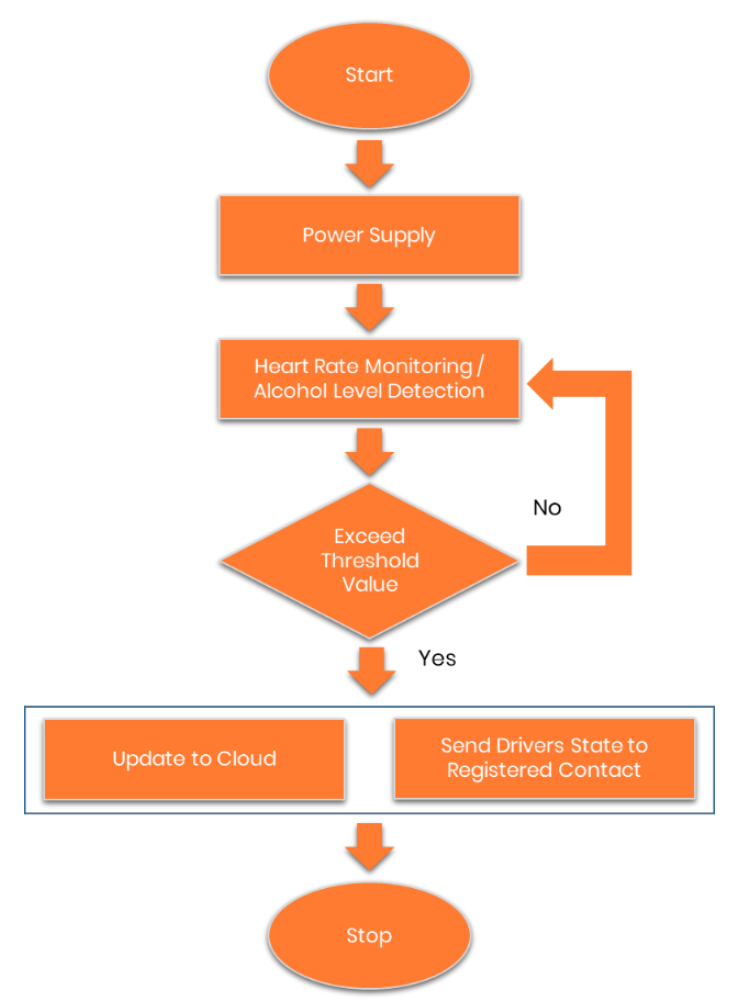

Figure 5. Flowchart

Figure 6 shows the breadboard diagram of the prototype development. Components such as microcontrollers and sensors are more easily seen on a breadboard diagram, which helps design the prototype. This may ensure that the required goals are met and the desired outcomes are achieved. The components connected by connectors are shown in Figure 6. 


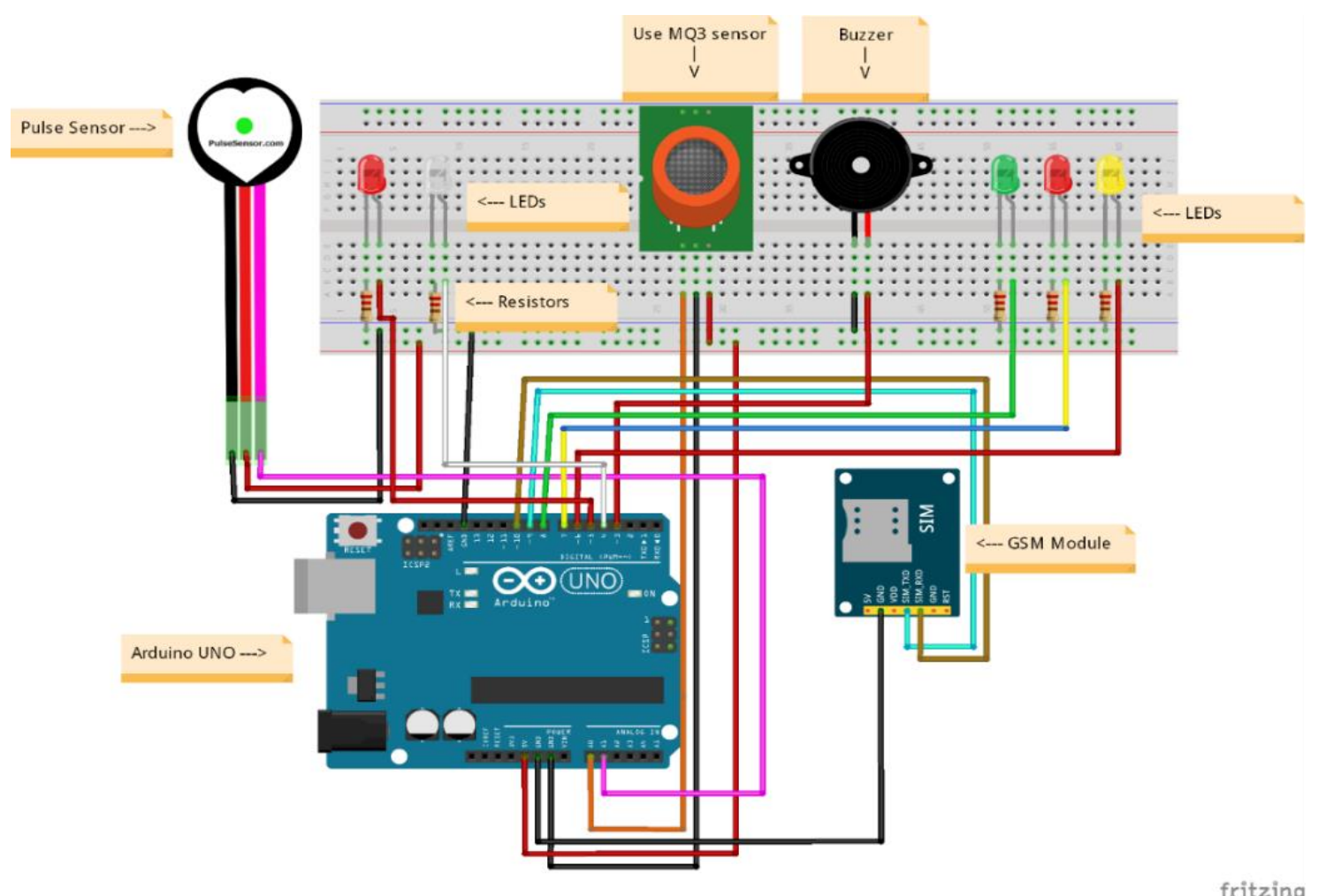

Figure 6. Breadboard diagram

\section{RESULT AND DISCUSSION}

The prototype comprises an arduino UNO microcontroller connected to the arduino IDE, which uploads and executes the programmes required to operate it. Putting one's finger on the pulse sensor is the initial step in this procedure. The tool is equipped with two LEDs, one of which emits red light and the other of which emits white light (placed inside the box). The red light switches on in the context of the heart rate are abnormal, while the white light constantly flashes to indicate the heart rate. On the other hand, the tool detects alcohol, placed near the steering to detect the concentration. The tool has three additional LEDs, where the green light is normal, blue light is slightly concentrated, and yellow is heavily concentrated. If the yellow light is constantly present, the information is sent to the emergency contact person and recorded in the cloud for profiling. The prototype itself is illustrated in Figure 7, which includes car steering and sensor positioning. Figures 8 and 9 demonstrate the outcome of heart rate monitoring and alcohol concentration detection, respectively.

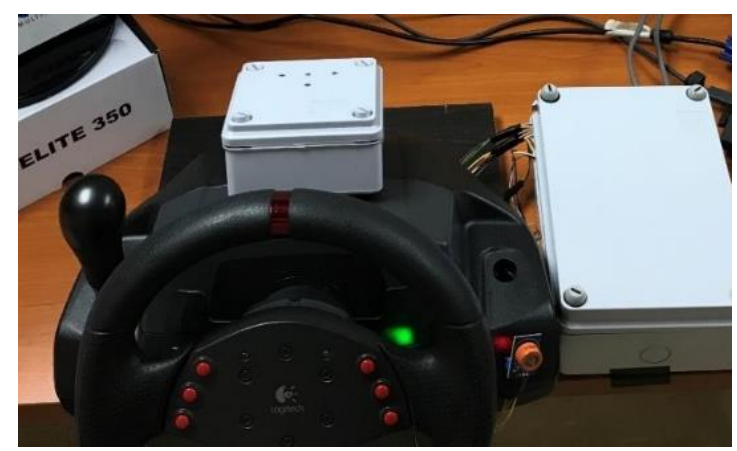

Figure 7. Prototype

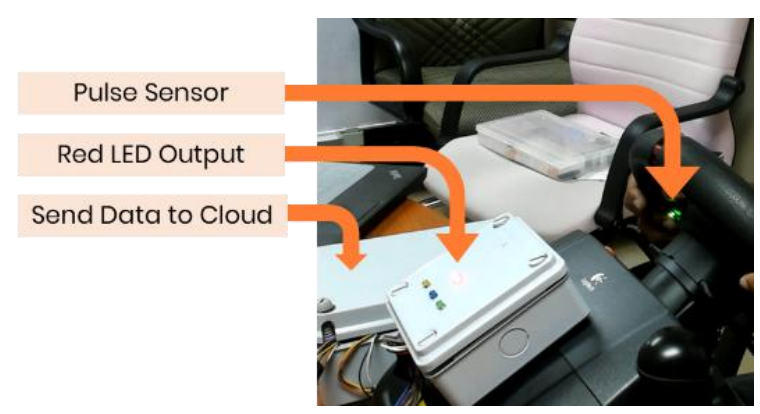

Figure 8. Heart rate testing condition 


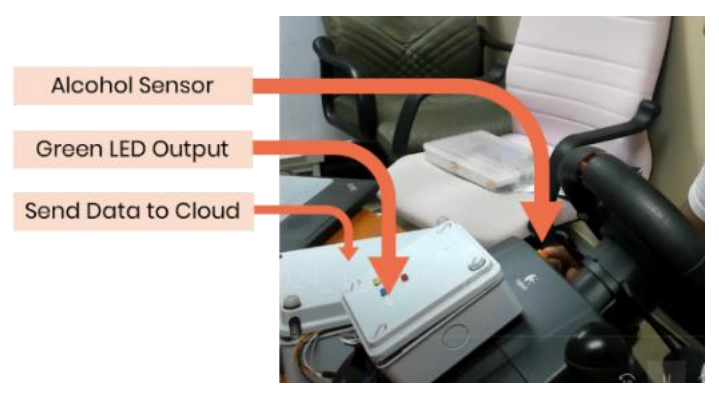

Figure 9. Alcohol testing condition

Although sensors deployed were cost-effective, it does nevertheless produce an adequeate output. Following the completion of the testing, the proposed prototype was found to be capable of monitoring the heart rate of any individual while also detecting the presence of alcohol in a laboratory-controlled environment. Table 3 depicts the total time required by the prototype to perform the whole measurement and sensing procedure.

Table 3. Prototype time required to complete the procedure

\begin{tabular}{cc}
\hline Procedure & Time Taken \\
\hline Monitoring of Heart Rate with Pulse Sensor & 1 to 3 seconds \\
Detection Alcohol Concentration with MQ3 Sensor & 1 to 3 seconds \\
\hline
\end{tabular}

\section{CONCLUSION}

The internet of things (IoT) makes transformative changes possible, and there is no doubt that the automotive industry is changing rapidly. This paper presents the conceptual approach of IoT for monitoring drivers regarding health abnormalities (heart rate) and alcohol concentration (level). Based on the test, the prototype developed can monitor the heart rate and detect alcohol concentration. An LED indication has demonstrated the heart rate and alcohol concentration output. If the threshold value is exceeded in this instance, the buzzer will sound, and the information will be transmitted to the cloud. The prototype is currently being tested in a monitored laboratory. As for the future direction where the developed prototype is packaged to be tested in the vehicle. This could identify the factors of any influence upon the readings.

\section{ACKNOWLEDGEMENTS}

This research was supported by KUIM/GPI/21/F1/02 grant. The authors fully acknowledged Kolej Universiti Islam Melaka (KUIM) the approved fund, which makes this important research viable and effective. The authors gratefully acknowledge the use of service and facilities of the Connected Car Services Research Group, Centre of Intelligent Cloud Computing at Multimedia University. The authors would also like to thank the anonymous reviewers for their valuable comments.

\section{REFERENCES}

[1] S. Nižetić, P. Šolić, D. L. D. I. González-de, and L. Patrono, "Internet of Things (IoT): Opportunities, issues and challenges towards a smart and sustainable future," Journal of Cleaner Production, vol. 274, p. 122877, 2020, doi: 10.1016/j.jclepro.2020.122877.

[2] A. A. Laghari, K. Wu, R. A. Laghari, M. Ali, and A. A. Khan, “A review and state of art of Internet of Things (IoT)," Archives of Computational Methods in Engineering, pp. 1-19, 2021, doi: 10.1007/s11831-021-09622-6.

[3] V. Sima et al., "Influences of the industry 4.0 revolution on the human capital development and consumer behavior: A systematic review," Sustainability, vol. 12, no. 10, p. 4035, 2020, doi: 10.3390/su12104035.

[4] B. Vaidya, and H. T. Mouftah, "IoT Applications and Services for Connected and Autonomous Electric Vehicles," Arabian Journal for Science and Engineering, pp. 1-11, 2019, doi: 10.1007/s13369-019-04216-8.

[5] V. Ratanavaraha and S. Suangka, "Impacts of accident severity factors and loss values of crashes on expressways in Thailand," IATSS research, vol. 37, no. 2, pp. 130-136, 2014, doi: 10.1016/j.iatssr.2013.07.001.

[6] A. K. Yadav and N. R. Velaga, "Effect of alcohol use on accelerating and braking behaviors of drivers," Traffic injury prevention, vol. 20, no. 4, pp. 353-358, 2019, doi: 10.1080/15389588.2019.1587167.

[7] M. F. Musa, S. A. Hassan, and N. Mashros, "The impact of roadway conditions towards accident severity on federal roads in Malaysia," PLoS one, vol. 15, no. 7, p. e0235564, 2020, doi: 10.1371/journal.pone.0235564

[8] K. Mokhtar et al., "A Perspective Analysis of Road Accident Using Data Envelopment Analysis," Journal of the Society of Automotive Engineers Malaysia, vol. 5 no. 1, pp. 41-56, 2021. 
[9] P. Sethi and S. R. Sarangi, "Internet of things: architectures, protocols, and applications," Journal of Electrical and Computer Engineering, vol. 2017, pp. 1-26, 2017, doi: 10.1155/2017/9324035.

[10] A. Salam, "Internet of things for sustainable human health," In Internet of Things for Sustainable Community Development, pp. 217-242, 2020, doi: 10.1007/978-3-030-35291-2_7.

[11] A. Rayes, and S. Salam, "Internet of things (IoT) overview," In Internet of Things From Hype to Reality, pp. 1-35, 2019, doi: 10.1007/978-3-319-99516-8_1.

[12] M. S. Alamsyah, M. Ikhlayel, and E. Setijadi, "Internet of Things-Based Vital Sign Monitoring System," International Journal of Electrical and Computer Engineering (IJECE), vol. 10, no. 6, pp. 5891-5898, 2020, doi: 10.11591/ijece.v10i6.pp5891-5898.

[13] H. J. Lee, and M. Kim, "The Internet of Things in a smart connected world," Internet of Things-Technology, Applications and Standardisation, vol. 91, pp. 91-104, 2018, doi: 10.5772/intechopen.76128.

[14] O. AlShorman et al., "A review of Internet of medical things (IoMT)-based remote health monitoring through wearable sensors: A case study for diabetic patients," Indonesian Journal of Electrical Engineering and Computer Science, vol. 20, no. 1, pp. 414-422, 2020, doi: 10.11591/ijeecs.v20.i1.pp414-422.

[15] S. Sharma and S. Sebastian, "IoT based car accident detection and notification algorithm for general road accidents," International Journal of Electrical and Computer Engineering, vol. 9, no. 5, 2019, doi: 10.11591/ijece.v9i5.pp4020-4026.

[16] R. R. Adiputra, S. Hadiyoso, and Y. S. Hariyani, "Internet of things: Low cost and wearable SpO2 device for health monitoring," International Journal of Electrical and Computer Engineering, vol. 8, no. 2, 939, 2018, doi: 10.11591/ijece.v8i2.pp939-945.

[17] H. Bishop, L. Boe, D. Stavrinos, and J. Mirman, "Driving among adolescents with autism spectrum disorder and attention-deficit hyperactivity disorder," Safety, vol. 4, no. 3, 40, 2018, doi: 10.3390/safety4030040.

[18] K. Patel, and J. E. Hipskind, "Cardiac arrest," StatPearls [Internet], 2020.

[19] H. R. Fajrin, B. S. Adi, H. Purwoko, and I. P. Sari, "Telemedicine-equipped android interface-based heart rate monitoring," Indonesian Journal of Electrical Engineering and Computer Science (IJEECS), vol. 21, no. 3, pp. 1332-1340, 2021, doi: 10.11591/ijeecs.v21.i3.pp1332-1340.

[20] K. E. MacLeod, W. A. Satariano, and D. R. Ragland, "The impact of health problems on driving status among older adults," Journal of transport and health, vol. 1, no.2, pp. 86-94, 2014, doi: 10.1016/j.jth.2014.03.001.

[21] F. Sanchis-Gomar, C. Perez-Quilis, R. Leischik, and A. Lucia, "Epidemiology of coronary heart disease and acute coronary syndrome," Annals of translational medicine, vol. 4, no. 13, pp. 1-12, 2016, doi: 10.21037/atm.2016.06.33.

[22] I. Mann, B. Sandler, N. Linton, and P. Kanagaratnam, "Drivers of atrial fibrillation: Theoretical considerations and practical concerns," Arrhythmia and electrophysiology review, vol. 7, no.1, pp. 49-54, 2018, doi: 10.15420/aer.2017.40.3.

[23] B. H. Ang, S. W. H. Lee, W. S. Chen, K. K. Yap, K. P. Song, and J. A. Oxley, "Retiring from driving and riding: be safe and not a risk," Journal of Transport \& Health, vol. 18, p. 100874. doi: 10.1016/j.jth.2020.100874.

[24] J. Speirs, "Safe, Attractive, and Sustainable Cities: A mobility-oriented approach," IGLUS (Innovative Governance of Large Urban Systems). vol. 8, no. 2, 2019, pp. 48-55, doi:10.12691/ajwr-8-2-1.

[25] N. Kamaruddin, A. W. A. Rahman, K. I. M. Halim, and M. H. I. M. Noh, "Driver Behaviour State Recognition based on Speech," TELKOMNIKA (Telecommunication, Computing, Electronics and Control), vol. 16, no. 2, pp. 852-861, 2018, doi: 10.12928/TELKOMNIKA.v16i2.8416

[26] R. S. A. Usmani, A. Saeed, A. M. Abdullahi, T. R. Pillai, N. Z. Jhanjhi, and I. A. T. Hashem, "Air pollution and its health impacts in Malaysia: a review," Air Quality, Atmosphere \& Health, vol. 13, no. 9, pp. 1093-1118, 2020, doi 10.1007/s11869-020-00867-x.

[27] F. Hamza Cherif, L. Hamza Cherif, M. Benabdellah, and G. Nassar, "Monitoring driver health status in real time," Review of scientific instruments, vol. 91, no. 3, pp. 035110, 2020, doi: 10.1063/1.5098308.

[28] M. E. Chowdhury et al., "Wearable real-time heart attack detection and warning system to reduce road accidents," Sensors, vol. 19, no. 12, 2780, 2019, doi: 10.3390/s19122780.

[29] L. Leicht et al., "Capacitive ECG monitoring in cardiac patients during simulated driving," IEEE Transactions on Biomedical Engineering, vol. 66, no. 3, pp. 749-758, 2018, doi: 10.1109/TBME.2018.2855661.

[30] F. Khan and S. H. Cho, "A detailed algorithm for vital sign monitoring of a stationary/non-stationary human through IR-UWB radar,” Sensors, vol. 17, no. 2, pp. 290, 2017, doi: 10.3390/s17020290.

[31] Y. Sun and X. Yu, "An innovative non-intrusive driver assistance system for vital signal monitoring," IEEE Journal of Biomedical And Health Informatics, vol. 18, no. 6, pp. 1932-1939, 2014, doi: 10.1109/JBHI.2014.2305403.

[32] X. Zhao, X. Zhang, and J. Rong, "Study of the effects of alcohol on drivers and driving performance on straight road," Mathematical problems in engineering, vol. 2014, pp. 1-10, 2014, doi: 10.1155/2014/607652

[33] N. Che-Him et al., "Factors Affecting Road Traffic Accident in Batu Pahat, Johor, Malaysia," In Journal of Physics: Conference Series, vol. 995, no. 1, p. 012033, 2018, doi: 10.1088/1742-6596/995/1/012033.

[34] Y. Zhou "Ride-sharing, alcohol consumption, and drunk driving," Regional Science and Urban Economics, vol. 85, no. 3, p. 103594, 2020, doi: 10.1016/j.regsciurbeco.2020.103594.

[35] F. Alonso, J. C. Pastor, L. Montoro, and C. Esteban, "Driving under the influence of alcohol: frequency, reasons, perceived risk and punishment," Substance abuse treatment, prevention, and policy, vol. 10, no. 1, pp. 1-9, 2015, doi: 10.1186/s13011-015-0007-4.

[36] H. Jiang et al., "Measuring and preventing alcohol use and related harm among young people in Asian countries: a thematic review," Global health research and policy, vol. 3, no. 1, pp. 1-14, 2018, doi: 10.1186/s41256-018-0070-2.

[37] M. A. M. Kassim, S. A. Hanan, M. S. Abdullah, and C. P. Hong, "Road accident proneness in Malaysia: A hypothesized model of driver's demographic profiles, aggressive driving and risky driving," AIP Conference Proceedings, 2021, vol. 2339, no. 1, pp. 020099, doi: 10.1063/5.0044555.

[38] L. L. Jie, C. W. Kern, and B. Mahmud, "A Study on the awareness of road safety for trucks transportation in Peninsular Malaysia," E3S Web of Conferences, vol. 136, p. 04087, 2019, doi: 10.1051/e3sconf/201913604087.

[39] M. A. M. Kassim, S. A. Hanan, and A. B. Aziz, "Driver's Personality Traits, Driving Anger, Risky Driving, Aggressive Driving and Road Accident Proneness in Malaysia: A Proposed Safety and Logistic Framework," Int. J Sup. Chain. Mgt, vol. 8, no. 5, pp. 1095,2019

[40] N. F. M. Soid, N. Isah, and Z. M. Jawi, “A study on Malaysian long-haul bus drivers' inappropriate driving behaviours and attitude towards traffic safety," Journal of Advanced Vehicle System, vol. 7, no. 1, pp. 1-10, 2019.

[41] P. Shukla et al., "Automatic Engine Locking System Through Alcohol Detection,” International Journal of Engineering Research and Technology (IJERT), vol. 9, no. 5, pp. 637-640, 2020, doi: 10.17577/IJERTV9IS050528.

[42] N. Mandal, A. Sainkar, O. Rane, and M. Vibhute, "Vehicle Tracking with Alcohol Detection and Seat Belt Control System," In 2020 International Conference for Emerging Technology (INCET), pp. 1-5, 2020, doi: 10.1109/INCET49848.2020.9154093.

[43] P. D. Rosero-Montalvo et al., "Multivariate approach to alcohol detection in drivers by sensors and artificial vision," In International Work-Conference on the Interplay Between Natural and Artificial Computation, pp. 234-243, 2019, doi: 10.1007/978-3-030-19651$6 \_23$. 
[44] H. Wakana, M. Yamada, and M. Sakairi, "Portable Alcohol Detection System with Breath-Recognition Function," In 2018 IEEE Sensors, pp. 1-4, 2018, doi: 10.1109/ICSENS.2018.8589877.

[45] K. Sandeep, P. Ravikumar, and S. Ranjith, "Novel drunken driving detection and prevention models using Internet of things," In 2017 International Conference on Recent Trends in Electrical, Electronics and Computing Technologies (ICRTEECT), pp. 145149, 2017, doi: 10.1109/ICRTEECT.2017.38.

\section{BIOGRAPHIES OF AUTHORS}

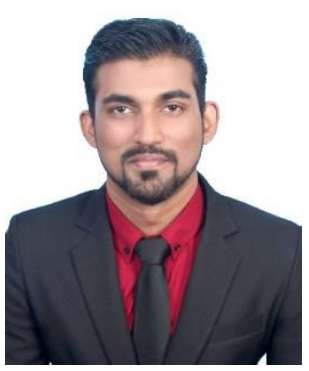

Sumendra Yogarayan (D) SC P is a Research Officer in the Faculty of Information Science and Technology, Multimedia University (MMU), Melaka, Malaysia, since 2019. He graduated from Multimedia University (MMU) with a Master of Science (Information Technology) in 2019 and a Bachelor of Information Technology (Security Technology) in 2015. He is currently pursuing his Doctor of Philosophy $(\mathrm{PhD})$ in Information Technology at Multimedia University (MMU). His research interest includes Intelligent Transportation Systems, Vehicular Ad Hoc Networks, Wireless Communication and Mesh Networks. He can be contacted at email: mastersumen@gmail.com.

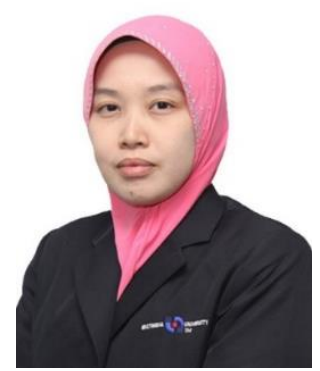

Ts. Dr. Siti Fatimah Abdul Razak (D) SC P has been a Lecturer at the Faculty of Information Science and Technology, Multimedia University, since 2005. She graduated from Multimedia University (MMU) with a Doctor of Philosophy (PhD) in Information Technology in 2018 and a Master of Information Technology (Science and System Management) in 2004. She is also an active member of the Centre for Intelligent Cloud Computing. Her research interest includes Vehicle Safety Applications, the Internet of Things, Rule Mining, Information Systems Development, and Educational Technology. She can be contacted at email: fatimah.razak@mmu.edu.my.

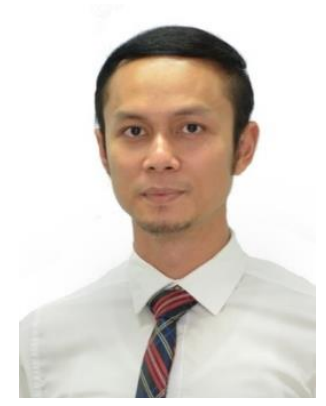

Prof. Madya. Ts. Dr. Afizan Azman (D) SC P is an Associate Professor at Kolej Universiti Islam Melaka, Malaysia. Previously he was the Chief of Executives at Melaka International College of Science and Technology. He graduated from Loughborough University with a Doctor of Philosophy (PhD) in Computer Science in 2013 and from University College of London with a Master of Information Technology in Computer Science in 2005. His research interests include Human-Computer Interaction, Artificial Intelligence, Vehicle systems and Technology, Data analytics, and the Internet of Things. He can be contacted at email: afizan@ kuim.edu.my.

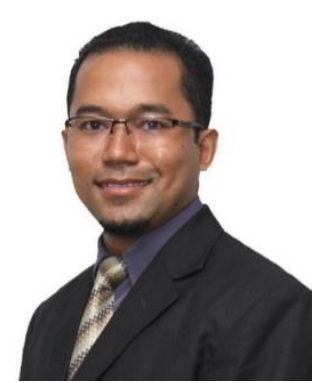

Ts. Mohd. Fikri Azli Abdullah (iD) SA SC P has been a Lecturer in the Faculty of Information Science and Technology at Multimedia University (MMU), Melaka, Malaysia, since 2005. He graduated from the University of Melbourne, Australia, with a master's in software system engineering. He was a researcher at Advance Network Lab at Chonnam National University, South Korea, in 2010. His research interest includes Mobile Computing, Image Processing and Pattern Recognition. $\mathrm{He}$ can be contacted at email: mfikriazli.abdullah@mmu.edu.my. 